\title{
Importance of Bovine Mastitis Associated Gene Expression Analysis - A Review
}

\author{
Kaiho Kaisa ${ }^{1}$, Harshit Kumar ${ }^{1}$, Manjit Panigrahi ${ }^{1}$, Triveni Dutt ${ }^{2}$ and Bharat Bhushan ${ }^{1 *}$ \\ ${ }^{1}$ Division of Animal Genetics, ICAR-Indian Veterinary Research Institute, Izatnagar, Bareilly, Uttar Pradesh, INDIA \\ ${ }^{2}$ Joint Director (Academic) Deemed University, ICAR-Indian Veterinary Research Institute, Izatnagar, Bareilly, \\ Uttar Pradesh, INDIA \\ "Corresponding author: B Bhushan; E-mail: bhushan.drbharat@gmail.com
}

Received: 02 Sept., 2020

Revised: 09 Feb., 2021

Accepted: 15 Feb., 2021

\begin{abstract}
Bovine mastitis has for a long period severely restrained production performance in the dairy enterprise. Despite improved management approaches and veterinary services, mastitis is still responsible for a major loss of the economy to the extent of worldwide. Genetic control as in development of protective immune mechanism and disease tolerant animal is considered an economic and prophylactic technique for health improvement management. We, therefore, need to recognise thoroughly the factors regulating the association between both the etiological agents and the host's mammary gland cells. Consequently, we need to determine differentially expressed genes during particular conditions in regard to mastitis. High-throughput transcriptome sequencing technique (RNA-Seq) has evolved as the main option for the analysis of differential gene expression setting the foundations for modern genetic research.
\end{abstract}

\section{HIGHLIGHTS}

( Mastitis in bovine is among the highly prevalent and devastating disease condition globally.

0 RNA-Seq is a preferred tool to map and quantify transcriptome profile.

0 To unfold the underlying functional elements of the genome entirely and their inter-relationship with the mastitis.

Keywords: Mastitis, Disease resistance, RNA sequencing, Gene expression

World milk production has steadily increased gradually with time. Global milk production achieved 852 million tonnes in 2019, an expansion of 1.4 percent against 2018, mainly due to increases in production from key producing regions like Asia. Milk production in Asia rose by 10 million tonnes to almost 360 million tonnes, or 2.9 percent against 2018, across over 90 percent coming from India and Pakistan (FAO, 2020). Besides the rising demand from fast growing urbanization, milk productivity is limited in several developing countries due to poor-quality feed services, diseases, limited market, and service access and the low genetic potential of milk producing dairy animals. Therefore, the rise in the supply to meet the demand should be viewed with caution as there are negative genetic associations between milk production and both fertility as well as development of diseases, suggesting that genetic depletion of fertility and health results mainly from selection for increased milk yield (Kumar et al., 2017) indicative of the mastitis effect is not only limited to the udder. Despite improvements in management practice and veterinary care, mastitis has also risen in many countries over the years. Genetic immune response regulation and disease resistant selection in livestock were very well known and viewed as an economical and standard treatment solution to improving animal health status. And to significantly improve dairy cattle selection with increased resistance, we need to first understand the associated gene (Buitenhuis et al., 2011; Kemper and Goddard, 2012; Goddard et al., 2016) and their expression profile in reaction to the pathogen-related to mastitis via transcriptome profiling.

How to cite this article: Kaisa, K., Kumar, H., Panigrahi, M., Dutt, T. and Bhushan, B. (2021). Importance of bovine mastitis associated gene expression analysis - a review. J. Anim. Res., 11(1): 01-09. Source of Support: None; Conflict of Interest: None 


\section{BOVINE MASTITIS}

The disease of great economic significance in the milk industry worldwide, is characterized as a mammary gland inflammatory disorder which can be induced by physical or chemical agents, but majority of the causes are infectious and mainly due to bacteria that gain entry into the mammary gland (MG), multiply and develop toxins that are harmful to the mammary gland (Bonnefont et al., 2011; Schukken et al., 2011; Jensen et al., 2013). Mastitis includes in the most frequent and expensive diseases in the dairy enterprise, with losses linked to decreased milk production, rejected milk, early slaughter, veterinarian treatment, and operating costs (Thompson-Crispi et al., 2014; Reshi et al., 2015). The outbreak of a zoonotic disease is also likely, as is the emergence of microbial drug resistant bacteria (Bishop et al., 2011). A huge array of pathogens induces mastitis and is epidemiologically grouped into contagious and environmental mastitis (Cervinkova et al., 2013). Contagious pathogens are those for which the principle reservoir is the udders of the sick cows. They transmit from cow to another cow, mainly while milking, and with flare-ups of clinical episodes appear to develop in recurrent subclinical infections. Staph. aureus, Strept. agalactiae, Corynebacterium bovis as well as Mycoplasma spp. contain infectious pathogens. Conversely, environmental mastitis can be generally characterized as those intramammary infections caused by pathogens whose primary reservoir is the cow's living environment. Such environmental pathogens comprise of E. coli, Strept. dysgalactiae \& $S$. uberis, Klebsiella spp., and nearly all infections produced by them are of clinical and short-lived (Abebe et al., 2016; Pal et al., 2019). These mastitis-causing diverse pathogens induce different immune responses in the mammary gland, which is why, the host requires highly specific pathogen-dependent responses for protection (Thompson-Crispi et al., 2014). We can also identify mastitis to be either clinical or subclinical (Wellnitz and Bruckmaier, 2012). Clinical mastitis may be specified by a sudden development, variation in the composition and presentation of milk, reduced production of milk, and the appearance of fundamental signs of inflammation in the contaminated mammary quarters. It is easily apparent and easy to identify. In comparison with that of sub-clinical manifestation, no visible symptoms are seen either on the udder or in milk, but the output of milk diminishes, and the somatic cells number increases. This is more frequent and seriously affects the milking animals (Banger et al., 2015; Tanamati et al., 2019; Kirsanova et al., 2020). For such reason as absence of any specific manifestation, the identification of sub-clinical form is a concern in milk animal management and in veterinary care (FAO, 2014).

Although several research has been done in dairy ruminants to understand the complex physiological and cellular activities that happen in the $\mathrm{MG}$ in reference to pathogens, the mechanisms of defence are still cryptic (Banos et al., 2017). Globally, mastitis is accountable for a significant financial loss of USD 33 billion (Pal et al., 2019). Notwithstanding strengthened management practices, the disease persists. Pal (2018) suggested that one of the biggest expenses to the dairy company globally was still acknowledged by the treatment and control of the disease mastitis.

\section{Escherichia coli (E. coli) and Staphylococcus aureus (S. aureus)}

$E$. coli and $S$. aureus are the most predominant Gramnegative and Gram-positive bacterial pathogens that infect the mammary cells in dairy cattle respectively (Jensen et al., 2013; Pal et al., 2019).

E. coli, the cause of acute clinical mastitis, is amongst the most common environmental pathogens (Ju et al., 2020). The E. coli-infected mastitic cows undergo serious systemic clinical symptoms; in the more severe cases, the disease can cause many deaths each year (Buitenhuis et al., 2011; Lippolis et al., 2018). This gram-negative bacterium constitutes the normal bovine intestinal flora and contaminates the environment through faeces, mostly bedding material. The cow is particularly vulnerable to coliform infections during the puerperal phase because the immune defence reaction is lower than normal at this time. Gram-negative bacteria produce endotoxin and the intramammary infection (IMI) normally results in extreme inflammatory reactions. Sometimes E. coli also can possibly cause subclinical mastitis, but these strains differ from those which cause clinical mastitis (Pal et al., 2019). E. coli produces lipopolysaccharide (LPS) endotoxin, the most potent immunostimulant (Arenas, 2012; Xu et al., 2019), and the key virulence factor eliciting clinical symptoms which is responsible for many of the inflammatory changes observed during coliform mastitis. The detection of LPS by Toll-like receptor 4 
(TLR4) (Panigrahi et al., 2014), mediated by a cluster of differentiation 14 (CD14), LPS Binding protein, and myeloid differentiation protein, is interconnected with the development of acute immune-response, enhanced SCC, activation of different leukocytes and immune related genes, release of cytokines (IL- 6 and TNF- $\alpha$ ), chemokines (CXCL5, CXCL8, and RANTES) and leukocytic chemoattractant (IL-8) (Alnakip et al., 2014; ThompsonCrispi et al., 2014).

$S$. aureus, a gram-positive bacterium, goes on being the major cause of subclinical mainly but as well as, clinical mastitis worldwide (Murphy et al., 2019; Pal et $a l ., 2019)$. The bacterium can quickly invade all types of cells in the MG and due to its intracellular localization in MG epithelial cells, it has a poor response to traditional antibiotic therapy. The intramammary infection induced with $S$. aureus progresses to chronic lifelong infection (Gilbert et al., 2013). The infected cows act as a reservoir from which transmission to humans can occur both from physical contact such as while milking by hand method and consumption of unpasteurized milk. IMIs by $S$. aureus are therefore not only potentially harmful to the animal but also to humans. $S$. aureus isolated from intramammary infections produces many potential virulence factors including enterotoxins, hemolysin, hyaluronidase, and leukocidins (Pal et al., 2019). Among the main immunostimulatory molecules, peptidoglycan (PGN) and lipoteichoic acid (LTA) have been proved to accelerate the development of inflammatory cytokines and chemokines by immune cells (Xu et al., 2019), including monocytes and macrophages. In vitro trials have also shown that LTA itself can trigger the expression in mammary epithelial cells (MECs) of many cytokines, few of which are IL$1 \beta$, IL-8, IL-6 and TNF- $\alpha$ (Bougarn et al., 2011). LTA has also been shown to greatly induce the release of CXCL1, CXCL2, CXCL3 and CXCL8 chemokines, which specifically target neutrophils (Kiku et al., 2016) and it increases the expression of IL-17 driven immune response genes in MECs in vitro (Bougarn et al., 2011). Toll-like receptor 2 (TLR2) plays a major part in the identification of LTA (Zhang et al., 2016).

\section{Recognition of Invading Mastitis Causative Bacteria by Host Innate Immune System}

Adequate immune functions are important for the protection of the host against IMIs. MG immunity is the consequence of the integration between non-specific and specific protective factors, along with the anatomical characteristics of its gland and the defence factors of both cellular as well as humoral aspects (Schukken et al., 2011). However, MG immune response differs through different lactation stages that occurs in dairy animals and is usually impaired via stress exposure and at the period of parturition and drying-off, thereby intensifying susceptibility to mastitis (Moosavi et al., 2014; Wu et al., 2020).

Innate and adaptive immunity are two essential components of MG host defence to defend against infections. The adaptive immune system (AIS) responds more competently to previously exposed threats yet responding to new threats is sluggish. However, the innate immune response is the very first line of defence towards the bacteria after violating the physical boundary of the teat canal and prior to when the AIS comes into action (Sordillo, 2018). This mechanism is implicated in a variety cascades of intracellular signal transduction that induce acute upregulation of many other innate immune elements, namely different leukocytes, molecules of adhesion and cytokinesis (Prince et al., 2011; Wellnitz et al., 2011).

The activation of an efficient and timely innate immune response (IIR) largely relies on recognising the infectious agent. MG IIR is prompted as pattern recognition receptors (PRRs) bind to pathogen-associated molecular patterns (PAMPs) considered bacterial motifs (Wellnitz and Bruckmaier, 2012). These motifs may be revealed during a microorganism's multiplication or degradation. A signalling transduction cascade is triggered by activation of these PRRs which contributes a vital part in controlling multiple signals and coordinating the expression of effector response genes, like cytokines, thus further stimulating local and systemic immune responses (Schukken et al., 2011; Stevens et al., 2011). Increases in PRR expression in the epithelia and tissues of affected bovine MGs and TLRs are the well-versed studied bovine PRRs and identify a large spectrum of PAMPs (Alnakip et al., 2014).

As pathogens enter the udder lumen via the teat channel, both immune and non-immune cells sense them, and the production of chemoattractant follows. Consequently, neutrophils migrate from the bloodstream to the area of 
infection. These cells possibly can generate phagocytes and exercise bactericidal activity by production of potent oxidative products (Prince et al., 2011). This huge recruitment of udder neutrophils brings about a drastic rise in the somatic cells count in the milk (SCC). Consequently, SCC were been employed widely as simple to use method for recognising mastitis and distinguishing among chronically infected and healthy or non-infected animals (Rainard et al., 2018).

There is ample evidence that the reaction of the host to IMI is subject to genetic control, but the underlying genetics for the resistance remains largely unclear. New progress in high throughput technology (RNA-Seq), which now facilitates the analysis of several thousands of infection-associated genes expression, has offered considerable insight into the host response to pathogens. Gene expression profiles for challenged mammary tissue (Kosciuczuk et al., 2017), milk cells (Wickramasinghe et al., 2012) and peripheral blood leukocytes (Wang et al., 2020) were studied using high throughput techniques such as RNA-Seq.

\section{RNA Sequencing (RNA-Seq)- A Significant Method to Analyse Mastitis Associated Gene Expression}

RNA molecules are highly vital components of all living cells. The primary aim of RNA investigation is to comprehend the identity and quantification of each RNA molecule in each cell under a particular condition. Most of what we know about RNA comes from biochemical examination of which a few numbers of specific molecules are studied. High-throughput approaches have also emerged which enable large-scale interrogation of RNA sequences (Hrdlickova et al., 2016).

Early gene expression analysis methods such as the expressed sequence tag (EST) technique described during 1990s analysis showed both the sequence and quantification of corresponding RNAs through partially sequencing complementary DNA (cDNA) clones. As in early 1990s, EST data played a crucial role. The high cost of the sequencing process, however, narrowed down the use of such expression processing. The Serial Analysis of Gene Expression (SAGE) technique was then introduced by significantly reducing the high cost of expression analysis per gene. However, with the advent of DNA microarray technology in the mid to later 1990s, replaced EST and SAGE techniques for gene expression research, primarily due to their much greater affordability for large-scale studies (Farkas et al., 2015; Hrdlickova et al., 2016). On the contrary, microarrays allow only the relative quantitation of transcripts and often depend on a properly annotated genome. It can only analyse transcripts of previously known, with no capability of recognizing alternative splice sites or new exons. Subsequently, the Next Generation Sequencing (NGS) or so-called deep sequencing i.e RNA-Seq, a paradigm shift in bio-medicine due to its ability to produce an incredible amount of data in a relatively short period has since then rapidly transformed RNA research. RNA-Seq provides low background signal, much more quantifiable and not limited to genomic sequences as contrast to DNA microarray-based methods (Nookaew et al., 2012; Adiconis et al., 2013; Van Dijk et al., 2014; Li et al., 2014; Han et al., 2015).

RNA-Seq has emerged as a widely used and important approach for characterizing transcripts, analysing gene expression and detecting RNA biogenesis and metabolism, offering powerful tools to uncover molecular pathways in development, differentiation and disease (Costa-Silva et al., 2017). RNA-Seq helps us to examine and discover transcriptome, the complete cellular content of RNAs, namely mRNA, rRNA and tRNA are few examples. Understanding the transcriptome is fundamental if we are to link information about our genome to the functional protein expression. RNA-Seq can show us which genes are switched on in a cell, their level of expression and when they are activated or shut (Ozsolak and Milos, 2011). Initially, the technique converts the RNA population to cDNA fragments (a cDNA library). This enables the RNA to be integrated into the NGS procedure. Then NGS analyses the library, generating short sequences that match to either one or both ends of the fragment. Subsequently, reads can be matched with a reference genome and assembled to generate an RNA sequence map that covers the transcriptome (Zhao et al., 2015), and the levels of expression for each gene are calculated.

Many tools and pipelines for the research of differential gene expression were been built from these sequenced data with the popularisation of RNA-Seq technology. Numerous studies have also been conducted lately on the transcriptome analysis of RNA-Seq-based mastitis in cattle (Chen et al., 2016; Fang et al., 2017; Lai et al., 2020; Wang et al., 2020). To state the obvious, RNA-Seq 
is excellently known as the superior microarray alternative and is possibly to persist as the favoured available option setting the foundations for modern genetic investigations.

Some studies related to mammary transcriptome profiling performed through RNA-Seq are explained briefly in table 1.

Table 1: Few research conducted to provide a transcriptome profile of the bovine mammary gland via RNA-Seq analysis
Mastitis is a result of the consequence of several cellular and soluble factors that operate together to remove invading microorganisms. Therefore, it may be necessary to integrate more biological information related to the studied complex traits to correlate the flow of biological information underlying this trait, which will supplement us find the appropriate genomic characteristics that

\begin{tabular}{|c|c|}
\hline References & Works done so far \\
\hline $\begin{array}{l}\text { Wickramasinghe et al. } \\
2012\end{array}$ & $\begin{array}{l}\text { Characterize the detailed bovine milk transcriptome in Holstein cows and demonstrated the capacity of milk } \\
\text { somatic cells to respond to various molecular functions according to the animal's biological needs. As during } \\
\text { transition lactation, a number of } 16,892 \text { genes were expressed, 19,094 genes during peak lactation, whereas, } \\
\text { during the late lactation about } 18,070 \text { genes were revealed. }\end{array}$ \\
\hline
\end{tabular}

Chen et al. 2016

Demonstrated that mammary stromal fibroblasts derived from mastic cows show inflammation-specific changes compared to those without mastitis from dairy cows and reflect their capacity for inflammation. And significantly enhanced levels of IL6 and TNF- $\alpha$ protein were detected by inflammation-associated fibroblasts (INFs) compared to normal fibroblasts. A total of 727 differentially expressed genes were discovered, 372 and 355 of which were up and down regulated in INFs, respectively.

Fang et al. $2017 \quad$ The research linked genome-wide association analysis (GWAS) to IMI-relevant RNA-Seq data and provided a framework for the integration of multiple data layers to give a clear perspective about the underlying genetic architecture of complex features, such as mastitis resistance and production of milk in dairy cattle. And genomic evidence has been given that the genes in the mammary gland which reacted to IMI were more associated with mastitis prevention than with the generation of milk.

Luoreng et al. $2018 \quad$ RNA-Seq was employed to screen the miRNA gene expression profile post-infection with $E$. coli at different point of times. A total of two hundred miRNAs articulated differentially were found at different times. The study is suggestive that these RNAs may regulate the mastitis development in dairy cows via various signal transduction pathways.

Xu et al. $2019 \quad$ Investigated variations in the global transcriptional response in regard with bovine mammary epithelial cells (BMECs) to LPS and LTA. In the LPS-treated group, they found 100 differentially expressed genes (DEGs) with 95 up-regulated and 5 down-regulated genes, while in the LTA-treated group, 24 DEGs have 12 upregulated and 12 down-regulated genes in contrast to control.

Han et al. $2020 \quad$ Transcriptome sequencing was conducted in healthy Chinese Holstein mammary glands to investigate the differentially expressed genes associated with inflammation and immunity. A number of 446 DEGs were found in Chinese Holstein's late-lactation mammary tissue (high SCC period) and during peak lactation (lower SCC period). Functional review showed 50 immunity and inflammation related DEGs, such as TLR2, IL-1, TNF- $\alpha$, CXCR1, CXCR2, CXCL8, SLC11A1 and TNFAIP3, TRAF6, RIP1.

Lai et al. 2020

Discovered that in modified and regular milk samples, 2-downregulated and 23-upregulated genes exhibit differential patterns of expression. 3 additional miRNAs has been found to be significantly associated with bovine mastitis.

Wang et al. $2020 \quad$ They conducted a study with the major goal for discovering candidate transcriptional blood-based biomarkers for $S$. aureus-induced bovine mastitis and offers new depth analysis of disease resistance genetics. 5 genes (EPOR, IFNL3, CCL26, IL9 and IL26) were shown to be enriched with cytokine-cytokine receptor pathway linked with immune response in 4 biological pathways, which may serve as molecular markers in breeding programmes. 
are highly enriched for causal variants (Fang et al., 2017). High throughput RNA-Seq has become one such important instrument for resolving complex biological issues by simultaneously evaluating thousands of genes expression in the tissue. Attribution of gene expression patterns would provide insight into their encoded proteins' biological roles and interacting proteins networks that influence cellular responses to extracellular stimuli.

The assessment of these studies would certainly require a lot of effort to make highly concrete conclusions about the functional utility of this knowledge to develop the standard approach of treatment or control of the animal disease. Moreover, cattle diseases like mastitis have a large effect on the immune reaction expression and other genes.

\section{Prospects}

The diversity in the prevalence and abundance of mastitiscausing organisms and the variation in host responses make mastitis a complex disease that continues to be a burden on the dairy sector. Generally, a disease management can be approached either of the two ways, by therapeutic approach that incorporates the high cost of veterinary diagnosis and services, antibiotic treatments, use of vaccine, etc., and the other way is via genetic approach of breeding for mastitis resistance. The earlier approach has instead contributed to the proliferation of numerous drug resistant strains of causative species (Chandrasekaran et al., 2014; Algammal et al., 2020) and failure of the vaccine to mount immunity against enormous mastitis-causing etiological agents (Mata, 2013), whereas the later approach was viewed to be an economic and prophylactic solution comparatively (Karthikeyan et al., 2016).

The initial step for such a strategy would be to correctly classify DEGs in recognising phenotypic variation under complex mastitis-related conditions. The discovery of the DEGs among the susceptible and resistant individuals offers key information for identifying candidates or marker for the underlying genetic basis of mastitis susceptibility or resistance, this lays the foundation for further modern genetic and mechanistic studies or approaches including genomic selection, marker-assisted selection or genomewide association studies (Bonnefont et al., 2011; Thompson-Crispi et al., 2014; Fang et al., 2017; Yan et al., 2020). To cite an example, Usman et al. (2017) also conducted a study suggesting that cytokines: IL-17F and
IL-17A could be effective mastitis resistance candidate genes, and in both milk and dual-purpose animals, large SNPs may deemed as useful genetic markers to manage mastitis. Likewise, the peripheral blood leukocyte (PBL) obtained from $S$. aureus positive mother daughter pairs and $S$. aureus control mother daughter pairs were subjected to transcriptomic evaluation and characterized using RNASeq by Wang et al. (2020). As follows, differential gene expression was assessed in a consecutive generation of dairy cattle: revealing contrasting DEGs. The study suggested that the genes outlined in the analysis may qualify as biomarkers of mastitis expression and may also include variations in the sequence which could be used for genetic enhancement of dairy cattle in mastitis resistance.

MG immune response is complicated as mastitis is subjected to a wide variety of infectious agents with various pathogenic mechanisms requiring complex pathogen-linked immune response. And the prevalence in dairy cattle is lesser with improved and balanced immune response and can be identified using high immune response (HIR) technology. Increased immune response is often characterised by significantly higher immunisation response, higher production of milk and colostrum, strengthened animal welfare, and higher quality of food to sustain the increasing population. As immunity is a major fitness trait, beneficial correlations with survival and reproduction are also widely noted (ThompsonCrispi et al., 2014). Strengthened immune response can be achieved by selecting disease resistance in livestock, which is taken into consideration to be the most relevant prophylactic strategy for improving animal welfare.

Therefore, in the near term, the task is to get a full discovery and detailed study of a significant systemic response in the mammary gland that affect the interaction among the host and various etiological agents. As it is expected that the understanding of RNA sequencing data and the position of functional SNPs or biomarkers in the host and the pathogen would connect the dots among the immune function and the relevant genes with potential to enhance resistance to pathogens specifically. The expertise of host-pathogen relationship in mastitis will probably be essential for the formation of new therapeutics and for performing genetic selection approach for mastitis resistance. The inclusion of mastitis resistance during the selection programs in Scandinavian countries has resulted in a greater economic response to selection (Sulabh, 2016). Such strategy can 
result in animal herd developing with increased resistance or tolerance to mastitis.

\section{CONCLUSION}

Mammary gland inflammation (mastitis) is one of dairy cattle's most common disease with an alarming economic loss in dairy industry worldwide. Genetic control of selection of immune response and disease tolerance is considered as one of the most economic and prophylactic measure to manage the disease. Mastitis tolerance, however, results from fine coordination of immune as well as inflammatory responses within a complex network of cell-gene interactions. Therefore, it is important to provide the scientific basis for generating immune intervention tools that improve the outcome of infections and defend against damages in bovine host mammary gland and the image of a dairy industry. With the rapid technological advances, given opportunity to study in more depth the expression of genes than ever, namely RNA-Seq have contributed to our understanding of the transcriptional characteristics and profile providing a basis for extending research scope to develop new targets for handling mastitis.

\section{REFERENCES}

Abebe, R., Hatiya, H., Abera, M., Megersa, B. and Asmare, K. 2016. Bovine mastitis: prevalence, risk factors and isolation of Staphylococcus aureus in dairy herds at Hawassa milk shed, South Ethiopia. BMC Vet. Res., 12: 270.

Adiconis, X., Borges-Rivera, D., Satija, R., DeLuca, D.S., Busby, M.A., Berlin, A.M., Sivachenko, A., Thompson, D. A., Wysoker, A., Fennell, T., Gnirke, A., Pochet, N., Regev, A. and Levin, J.Z. 2013. Comparative analysis of RNA sequencing methods for degraded or low input samples. Nat. Meth., 10(7): 623-629.

Algammal, A.M., Enany, M.E., El-Tarabili, R.M., Ghobashy, M. O. I. and Helmy, Y. A. 2020. Prevalence, antimicrobial resistance profiles, virulence and enterotoxins-determinant genes of MRSA isolated from subclinical bovine mastitis in Egypt. Pathog., 9(5): 362.

Alnakip, M.E., Quintela-Baluja, M., Böhme, K., Fernández-No, I., Caamaño-Antelo, S., Calo-Mata, P. and Barros-Velázquez, J. 2014. The immunology of mammary gland of dairy ruminants between healthy and inflammatory conditions. $J$. Vet. Med., pp. 31.
Arenas, J. 2012. The role of bacterial lipopolysaccharides as immune modulator in vaccine and drug development. Endocr. Metab. Immune Disord. Drug Target, 12: 221-235.

Bangar, Y.C., Singh, B., Dohare, A.K. and Verma, M.D. 2015. A systematic review and meta-analysis of prevalence of subclinical mastitis in dairy cows in India. Trop. Anim. Health Prod., 47: 291-297.

Banos, G., Bramis, G., Bush, S.J., Clark, E.L., McCulloch, M.E.B., Smith, J., Schulze, G., Arsenos, G., Hume, D.A. and Psifidi, A. 2017. The genomic architecture of mastitis resistance in dairy sheep. BMC Genomics, 18: 624.

Bishop, S.C., Axford, R.F.E., Nicholas, F.W. and Owen, J. B. 2011. Breeding for disease resistance in farm animals. 3rd Ed., CABI publishing, Wallingford, U.K., pp. 3-32.

Bonnefont, C.M.D., Toufeer, M., Caubet, C., Foulon, E., Tasca, C., Aurel, M.R., Bergonier, D., Boullier, S., Robert-Granié, C., Foucras, G. and Rupp, R. 2011. Transcriptomic analysis of milk somatic cells in mastitis resistant and susceptible sheep upon challenge with Staphylococcus epidermidis and Staphylococcus aureus. BMC Genomics, 12: 208.

Bougarn, S., Cunha, P., Gilbert, F. B., Harmache, A., Foucras, A. and Rainard, P. 2011. Staphylococcal associated molecular patterns enhance expression of immune defense genes induced by IL-17 in mammary epithelial cells. Cytokine, 56(3): 749-759.

Buitenhuis, B., Røntved, C.M., Edwards, S.M., Ingvartsen, K.L. and Sorensen, P. 2011. In depth analysis of genes and pathways of the mammary gland involved in the pathogenesis of bovine Escherichia coli- mastitis. BMC Genomics, 12: 130.

Cervinkova, D., Vlkova, H., Borodacova, I., Makovcova, J., Babak, V., Lorencova, A., Vrtkova, I., Marosevic, D. and Jaglic, Z. 2013. Prevalence of mastitis pathogens in milk from clinically healthy cows. Vet. Med., 58(11): 567-575.

Chandrasekaran, D., Venkatesan, P. and Tirumurugaan, K.G. 2014. Pattern of antibiotic resistant mastitis in dairy cows. Vet. World, 7(6): 389-394.

Chen, Q., He, G., Zhang, W., Xu, T., Qi, H., Li, J., Zhang, Y. and Gao, M. Q. 2016. Stromal fibroblasts derived from mammary gland of bovine with mastitis display inflammation-specific changes. Sci. Rep., 6: 27462.

Costa-Silva, J., Domingues, D. and Lopes, F.M. 2017. RNA-Seq differential expression analysis: an extended review and a software tool. PLoS One, 12: e0190152.

Fang, L., Sahana, G., Su, G., Yu, Y., Zhang, S., Lund, M.S. and Sørensen, P. 2017. Integrating sequence based GWAS and RNA-Seq provides novel insights into the genetic basis of mastitis and milk production in dairy cattle. Sci. Rep., 7: 45560. 
Farkas, M.H., Au, E.D., Sousa, M.E. and Pierce, E.A. 2015. RNA-Seq: improving our understanding of retinal biology and disease. Cold Spring Harb. Perspect. Med., 5: a017152.

FAO, 2014. Food and agriculture organization of the united nations, animal production and health: impact of mastitis in small scale dairy production systems, FAO, Rome Italy.

FAO, 2020. Food and agriculture organization of the united nations, dairy market review: overview of global dairy market developments, FAO, Rome Italy.

Gilbert, F.B., Cunha, P., Jensen, K., Glass, E.J., Foucras, G., Robert-Granié, C., Rupp, R. and Rainard, P. 2013. Differential response of bovine mammary epithelial cells to Staphylococcus aureus or Escherichia coli agonists of the innate immune system. Vet. Res., 44(1): 40.

Goddard, M., Kemper, K., MacLeod, I., Chamberlain, A. and Hayes, B. 2016. Genetics of complex traits: prediction of phenotype, identification of causal polymorphisms and genetic architecture. Proc. Biol. Sci., 27: 283.

Han, Z., Fan, Y., Yang, Z., Loor, J. J. and Yang, Y. 2020. Mammary transcriptome profile during peak and late lactation reveals differentially expression genes related to inflammation and immunity in chinese holstein. Anim., 10: 510 .

Han, Y., Gao, S., Muegge, K., Zhang, W. and Zhou, B. 2015. Advanced applications of RNA sequencing and challenges. Bioinform. Biol. Insights., 9: 29-46.

Hrdlickova, R., Toloue, M. and Tian, B. 2016. RNA-Seq methods for transcriptome analysis. Wiley Interdiscip. Rev. $R N A$, 8: e1364.

Jensen, K., Günther, J., Talbot, R., Petzl, W., Zerbe, H., Schuberth, H.J., Seyfert, H.M. and Glass, E.J. 2013. Escherichia coli- and Staphylococcus aureus-induced mastitis differentially modulate transcriptional responses in neighbouring uninfected bovine mammary gland quarters. BMC Genomics, 14: 36.

Ju, Z., Jiang, Q., Wang, J., Wang, X., Yang, C., Sun, Y., Zhang, Y., Wang, C., Gao, Y., Wei, X., Hou, M. and Huang, J. 2020. Genome-wide methylation and transcriptome of blood neutrophils reveal the roles of DNA methylation in affecting transcription of protein-coding genes and miRNAs in E. coliinfected mastitis cows. BMC Genomics, 21: 102.

Karthikeyan, A., Radhika, G., Aravindhakshan, T.V. and Anilkumar, K. 2016. Expression profiling of innate immune genes in milk somatic cells during subclinical mastitis in crossbred dairy cows. Anim. Biotechnol., 27(4): 303-309.

Kemper, K. E. and Goddard, M. E. 2012. Understanding and predicting complex traits: knowledge from cattle. Hum. Mol. Genet., 21: 45-51.

Kiku, Y., Nagasawa, Y., Tanabe, F., Sugawara, K., Watababe, A., Hata, E., Ozawa, T., Nakajima, K., Arai, T. and Hayashi, T. 2016. The cell wall component lipoteichoic acid of
Staphylococcus aureus induces chemokine gene expression in bovine mammary epithelial cells. J. Vet. Med. Sci., 78(9): $1505-1510$

Kirsanova, E., Boysen, P., Johansen, G.M., Heringstad, B., Lewandowska-Sabat, A. and Olsaker, I. 2020. Expression analysis of candidate genes for chronic subclinical mastitis in Norwegian Red cattle. J. Dairy Sci., 103(10): 9142-9149.

Kosciuczuk, E. M., Lisowski, P., Jarczak, J., Majewska, A., Rzewuska, M., Zwierzchowski, L. and Bagnicka, E. 2017. Transcriptome profiling of Staphylococci infected cow mammary gland parenchyma. BMC Vet. Res., 13:161.

Kumar, N., Manimaran, A., Kumaresan, A., Jeyakumar, S., Sreela, L., Mooventhan, P. and Sivaram, M. 2017. Mastitis effects on reproductive performance in dairy cattle: a review. Trop. Anim. Health. Prod., 49: 663-673.

Lai, Y. C., Lai, Y. T., Rahman, M. M., Chen, H. W., Husna, A. A., Fujikawa, T., Ando, T., Kitahara, G., Koiwa, M., Kubota, C. and Miura, N. 2020. Bovine milk transcriptome analysis reveals microRNAs and RNU2 involved in mastitis. The FEBS J., 287: 1899-1918.

Li, S., Tighe, S. W., Nicolet, C.M., Grove, D., Levy, S., Farmerie, W., Viale, A., Wright, C., Schweitzer, P. A., Gao, Y., Kim, D., Boland, J., Hicks, B., Kim, R., Chhangawala, S., Jafari, N., Raghavachari, N., Gandara, J., Garcia-Reyero, N., Hendrickson, C., Roberson, D., Rosenfeld, J., Smith, T., Underwood, J.G., Wang, M., Zumbo, P., Baldwin, D.A., Grills, G.S. and Mason, C.E. 2014. Multi-platform assessment of transcriptome profiling using RNA-seq in the ABRF nextgeneration sequencing study. Nat. Biotechnol., 32: 915-925.

Lippolis, J.D., Holman, D.B., Brunelle, B. W., Thacker, T.C., Bearson, B.L., Reinhardt, T.A., Sacco, R. E. and Casey, T.A. 2018. Genomic and transcriptomic analysis of Escherichia coli strains associated with persistent and transient bovine mastitis and the role of colanic acid. Infect. Immun., 86: e00566-17.

Luoreng, Z.M., Wang, X. P., Mei, C.G. and Zan, L.S. 2018. Expression profiling of peripheral blood miRNA using RNAseq technology in dairy cows with Escherichia coliinduced mastitis. Sci. Rep., 8: 12693.

Mata, F. 2013. Mastitis vaccination in dairy cattle: a metaanalysis of field case-control trials. Rev. Port. Ciênc. Vet., 108: $17-22$.

Moosavi, M., Mirzaei, A., Ghavami, M. and Tamadon, A. 2014. Relationship between season, lactation number and incidence of clinical mastitis in different stages of lactation in a holstein dairy farm. Vet. Res. Forum, 5(1): 13-19.

Murphy, M. P., Neidziela, D.A., Leonard, F.C. and Keane, O.M. 2019. The in vitro host cell immune response to bovineadapted Staphylococcus aureus varies according to bacterial lineage. Sci. Rep., 9: 6134. 
Nookaew, I., Papini, M., Pornputtapong, N., Scalcinati, G., Fagerberg, L., Uhlen, M. and Nielsen J.A. 2012. Comprehensive comparison of RNA-Seq-based transcriptome analysis from reads to differential gene expression and cross comparison with microarrays: a case study in Saccharomyces cerevisiae. Nucleic Acids Res., 40: 10084-10097.

Ozsolak, F. and Milos, P.M. 2011. RNA sequencing: advances, challenges and opportunities. Nat. Rev. Genet., 12(2): 87-98.

Pal, M. 2018. Mastitis: A major production disease of dairy animals. Agr. World, 4: 46-51.

Pal, M., Regasa, A. and Gizaw, F. 2019. Etiology, pathogenesis, risk factors, diagnosis and management of bovine mastitis: A comprehensive review. Int. J. Anim. Vet. Sci., 6: 40-55.

Panigrahi, M., Sharma, A. and Bhushan, B. 2014. Molecular characterization and expression profile of partial TLR4 gene in association to mastitis in crossbred cattle. Anim. Biotechnol., 25(3): 188-199.

Prince, L.R., Whyte, M.K., Sabroe, I. and Parker, L. C. 2011. The role of TLRs in neutrophil activation. Curr. Opin. Pharmacol., 11(4): 397-403.

Rainard, P., Foucras, G., Boichard, D. and Rupp, R. 2018. Invited review: Low milk somatic cell count and susceptibility to mastitis. J. Dairy Sci., 101(8): 6703-6714.

Reshi, A. A., Husain, I., Bhat, S. A., Rehman, M. U., Razak, R., Bilal, S. and Mir, M. R. 2015. Bovine mastitis as an evolving disease and its impact on the dairy industry. Int. J. Cur. Res. Rev. 7(5): 48-55.

Schukken, Y.H., Günther, J., Fitzpatrick, J., Fontaine, M. C., Goetze, L., Holst, O., Leigh, J., Petzl, W., Schuberth, H. J., Sipka, A., Smith, D.G.E., Quesnell, R., Watts, J., Yancey, R., Zerbe, H., Gurjar, A., Zadoks, R.N. and Seyfert, H.M. 2011. Host-response patterns of intramammary infections in dairy cows. Vet. Immunol. Immunopathol., 144(3-4): 270- 289.

Sordillo, L.M. 2018. Mammary gland immunobiology and resistance to mastitis. Vet. Clin. Food Anim., 34(3): 507-523.

Stevens, M.G.H., Peelman, L.J., Spiegeleer, B. De., Pezeshki, A., Van De Walle, G.R., Duchateau, L. and Burvenich, C. 2011. Differential gene expression of the toll-like receptor-4 cascade and neutrophil function in early- and mid-lactating dairy cows. J. Dairy Sci., 94(3): 1277-1288.

Sulabh, S. 2016. Gene expression profiling of immune related genes by in vitro challenge of PBMCS with E. coli and $S$. aureus agonists causing mastitis. Ph. D. thesis. Submitted to deemed university ICAR-Indian veterinary research institute Izatnagar - 243122 (U.P.), India.

Tanamati, F., Stafuzza, N.B., Gimenez, D. F. J., Stella, A.A.S., Santos, D.J.A., Ferro, M. I.T., Albuquerque, L.G., Gasparino, E. and Tonhati, H. 2019. Differential expression of immune response genes associated with subclinical mastitis in dairy buffaloes. Anim., 13(8): 1651-1657.
Thompson-Crispi, K., Atalla, H., Miglior, F. and Mallard, B.A. 2014. Bovine mastitis: frontiers in immunogenetics. Front Immunol., 5: 493.

Usman, T. Wang, Y., Liu, C., He, Y., Wang, X., Dong, Y., Wu, H., Liu, A. and Yu, Y. 2017. Novel SNPs in IL-17F and IL-17A genes associated with somatic cell count in Chinese Holstein and Inner-Mongolia Sanhe cattle. J. Anim. Sci. Biotechnol., 8: 5 .

Van Dijk, E. L., Jaszczyszyn, Y. and Thermes, C. 2014. Library preparation methods for next-generation sequencing: tone down the bias. Exp. Cell Res., 322(1): 12-20.

Wang, D., Liu, L., Augustino, S. M. A., Duan, T., Hall, T.J., MacHugh, D.E., Dou, J., Zhang, Y., Wang, Y. and Yu, Y. 2020. Identification of novel molecular markers of mastitis caused by Staphylococcus aureus using gene expression profiling in two consecutive generations of Chinese Holstein dairy cattle. J. Anim. Sci. Biotechnol., 11: 98.

Wellnitz, O., Arnold, E.T. and Bruckmaier, R.M. 2011. Lipopolysaccharide and lipoteichoic acid induce different immune responses in the bovine mammary gland. J. Dairy Sci. 94(11): 5405-5412.

Wellnitz, O. and Bruckmaier, R.M. 2012. The innate immune response of the bovine mammary gland to bacterial infection. Vet. J., 192(2): 148-152.

Wickramasinghe, S., Rincon, G., Islas-Trejo, A. and Medrano, J. F. 2012. Transcriptional profiling of bovine milk using RNA sequencing. BMC Genomics, 13: 45.

Wu, Y., Chen, J., Sun, Y., Dong, X., Wang, Z., Chen, J. and Dong, G. 2020. PGN and LTA from Staphylococcus aureus induced inflammation and decreased lactation through regulating DNA methylation and histone $\mathrm{H} 3$ acetylation in bovine mammary epithelial cells. Toxins, 12(4): 238.

Xu, T., Deng, R., Li, X., Zhang, Y. and Gao, M.Q. 2019. RNASeq analysis of different inflammatory reactions induced by lipopolysaccharide and lipoteichoic acid in bovine mammary epithelial cells. Microb. Pathog., 130: 169-177.

Yan, Z., Huang, H., Freebern, E., Santos, D.J.A., Dai, D., Si, J., Ma, C., Cao, J., Guo, G., Liu, G.E., Ma, L., Fang, L. and Zhang, Y. 2020. Integrating RNA-Seq with GWAS reveals novel insights into the molecular mechanism underpinning ketosis in cattle. BMC Genomics, 21: 489.

Zhang, W., Li, X., Xu, T., Mengru, M., Zhang, Y. and Gao, M. Q. 2016. Inflammatory responses of stromal fibroblasts to inflammatory epithelial cells are involved in the pathogenesis of bovine mastitis. Exp. Cell Res., 349(1): 45-52.

Zhao, S., Zhang, Y., Gordon, W., Quan, J., Xi, H., Du, S., David Von, S. and Zhang, B. 2015. Comparison of stranded and nonstranded RNA-Seq transcriptome profiling and investigation of gene overlap. BMC Genomics, 16: 675. 
